\title{
FEATURES OF LOAD AND WEAR OF MAIN PROPULSION DEVICES ON SEA-GOING SHIPS WITH PISTON COMBUSTION ENGINES AND THEIR IMPACT ON CHANGES IN TECHNICAL STATES OF THE SYSTEMS
}

Jerzy Girtler

Gdańsk University of Technology, Poland

\begin{abstract}
The paper presents the specificity of operation of propulsion systems of seagoing ships which causes the need to control the load on them, especially on their engines called main engines. The characteristics of the load on the propulsion systems, especially on the main engines as well as on the shaft lines and propellers driven by the engines, along with the process of wear in tribological joints (sliding tribological systems) of the machines have been described herein. Using examples of typical types of wear (both linear and volumetric) for the tribological systems of this sort, interpretation of states of their wear has been provided with regards to the wear levels defined as acceptable, unacceptable and catastrophic. The following hypotheses have been formulated: 1) hypothesis explaining necessity to consider the loads on the systems under operation as stochastic processes; 2) hypothesis explaining a possibility of considering the processes as stationary; and 3) hypothesis explaining why it can be assumed that a given technical state of any tribological system can be considered as dependent only on the directly preceding state and stochastically independent of the states that existed earlier. Accepting the hypotheses as true, a four-state continuous-time semi-Markov process has been proposed in the form of a model of changes in condition of a propulsion system (PS) of any ship. The model includes the most significant states affecting safety of a ship at sea, such as: $s_{0}-P S$ ability state, $s_{1}-P S$ disability state due to damage to the main engine (ME), $s_{2}$ - PS disability state due to damage to the shaft line (SL) and $s_{3}$ - PS disability state due to damage to the propeller ( $P$ ). Probability of occurrence (changes) of the states has also been demonstrated.
\end{abstract}

Keywords: load, reciprocating internal combustion engine, seagoing ship, propulsion system of a ship, wear

\section{INTRODUCTION}

Propulsion systems on sea-going ships are consisted of one propulsion unit (Fig. 1) or many propulsion units of various design solutions $[1,18,37]$. In case of large commercial ships like general cargo ships, bulk carriers, containerships, tankers, the one-engine, one-shaft (one-propeller) propulsion systems without reduction gear are used. The main devices of such propulsion systems are: main engine $(S G)$, screw propeller $(\mathrm{SN})$ and shaftline connecting $S G$ with $S N$ (Fig. 1). The main engine is a slow-speed, self -ignition combustion engine of large or great power, and the screw propeller more and more often is that of controllable pitch $(C P P)$. The shaftline of the propulsion systems in question is consisted of such devices as: thrust shaft and propeller shaft (sometimes intermediate shaft), thrust bearing and shaft journal bearings, clutch, brake and turning gear. Excessive linear (surface) wear and/ or volumetric wear of any of the above mentioned devices of an arbitrary propulsion system of every ship, causes failure of the system.

Rational operation of propulsion systems on sea-going ships consists in, a.o., the appropriate controlling of changes in their energy states and, resulting from them, thermal and mechanical loads affecting their devices, especially their main tribological links (systems). In the case of engines, the following belong to such links: pistons - piston rings - cylinder sleeves as well as main and crankshaft bearings. In the case of controllable pitch propellers ( $S N o S N)$ with 
electro-hydraulical control over the propeller pitch change mechanism (MZSS), the following should be counted among the crucial tribological links: piston- cylinder link of MZSS ram, piston-cylinder link of distribution slider and propeller blade bearings. And, in the case of shaftline the most important tribological links are: thrust bearing and journal bearings $[4,13,15,27,36,37,43]$.

Run of wear processes in the above mentioned systems, both concerning surface and volumetric wear, strictly depends on execution of control process over thermal and mechanical loads of the specified devices of ship propulsion systems. Wear processes of any propulsion system of any ship result in change of technical state of the system. In the most simple manner, the following states may be distinguished: the serviceability state $\left(s_{0}\right)$ of the propulsion system $(U N)$, its unserviceability state $\left(s_{1}\right)$ resulting from failure of the main engine $(S G)$, its unservicability state $\left(s_{2}\right)$ resulting from failure of the shaftline $(L W)$ and its unservicability state $\left(s_{3}\right)$ resulting from failure of the controllable pitch propeller $(S N o S N)$. In this situation it is interesting for propulsion system's user how big probabilities (respectively $-P_{0}, P_{1}, P_{2}, P_{3}$ ) of occurrence of the mentioned technical states in a longer duration time of its operation (theoretically for $t \rightarrow \infty$ ), are.

The probabilities mean: $P_{0}-$ probability of $U N$ serviceability, $P_{1}$ - probability of $U N$ unserviceability due to $S G$ failure, $P_{2}$ - probability of $U N$ unserviceability due to $L W$ failure, $P_{3}$ - probability of $U N$ unserviceability due to $S N$ failure. Determination of the probabilities requires to use a mathematical model assumptions for which would be appropriate to features of load and wear processes in such devices of ship propulsion systems (Fig. 1) as the main engine $(S G)$, shaftline $(L W)$ and controllable pitch propeller $(S N o S N)$.

\section{FEATURES OF LOADS OF PROPULSION SYSTEMS ON SEA-GOING SHIPS, WHICH ARE MAIN CAUSES OF THEIR FAILURES}

Features of loads of propulsion systems on sea-going ships, considered to be main causes of their failures, may be described in a similar way like qualities of loads of tribological links in piston-crankshaft systems of main engines $(S G)$, which were already discussed in detail in [18]. A schematic diagram of a propulsion system, such as that shown in Fig. 1, was presented in $[1,42]$. Fig. 1 shows also exemplary causes of $U N$ unserviceability state: a - failure of $S N O S N$, b - failure of $S G$. In the case of large commercial ships (tankers, bulk carriers, containerships) such units simultaneously serve as their propulsion systems. Loads on propulsion systems of every sea-going ship are also so significantly varying during ship operation as loads in $S G$ tribological links $[11,15,18,26$, $27,36,37,40,41]$. The loading depends on atmospheric and sea conditions which are especially unfavourable during storm weather, as well as on effective power of the engine loaded within a given working area. The power output depends on fuel dose as well as wear of tribological links, especially those of main engines, such as pistons, rings and cylinder sleeves as well as main and crankshaft bearings.

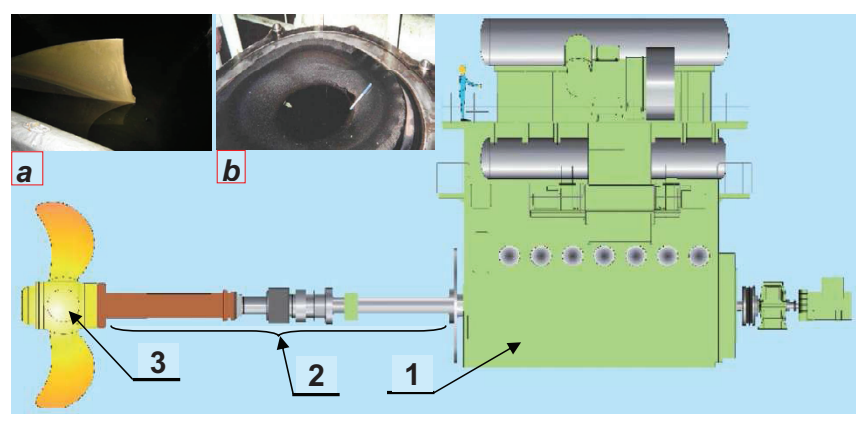

Fig. 1. Propulsion system (UN) usually applied on large commercial ships (tankers, general cargo ships, bulk carriers, containerships): 1 - slow-speed, two-stroke main engine (SG),

2 - shaftline (LW), 3 - controllable pitch screw propeller (SNoSN), $a-a$ view on a broken blade of the SNoSN, $b$ - a view on a SG piston head with a burnt -though hole

Excessive wear and a failure resulting from the loading upon any device of the propulsion system (SG, LW, SNoSN) causes failure of the system. The determining of the mentioned probabilities $P_{0}, P_{1}, P_{2}, P_{3}$ requires to work out such mathematical model as to reflect physical feature of the loading upon the system $U N$ and first of all on tribological links of the $S G$ - the crucial device.

Both the mechanical $\left(Q_{M}\right)$ and thermal $\left(Q_{C}\right)$ loads upon elements of tribological links of the controllable pitch propellers (SNoSN), shaftline (LW) [41, 43, 47] and main engines $(S G)$ vary randomly, sometimes in a broad range, along with time $[6,16,21,24,22,30,40]$.

Therefore during operation phase the loading $Q(t)$ upon tribological links of such engines as well as those of shaftlines and screw propellers should be considered to be a stochastical process comprising its mechanical component $Q_{M}(t)$ an thermal one $Q_{C}(t)$, that may be expressed as follows [18]

$$
Q(t)=f\left[Q_{M}(t), Q_{C}(t)\right]
$$

where:

$Q$ - loading upon the engine;

$Q_{M}$ - mechanical loading upon the engine;

$Q_{C}$ - thermal loading upon the engine;

$t$ - duration time of engine operation.

Hence, in empirical investigations on the loading, two stochastic processes $\left\{Q_{M}(t): t \geq 0\right\}$ and $\left\{Q_{C}(t): t \geq 0\right\}$ being components of the process $\{Q(t): t \geq 0\}$, can be considered[18].

As results from the considerations presented in [18], it is possible to formulate a hypothesis $H_{1}$ which says that: loading process of any propulsion system (i.e. its main engine, shaftline, screw propeller) is stochastic process because values of the loading upon the system, assigned to arbitrary time instant $t$, are random variables.

In case of every self-ignition engine, different values of its operational indices (parameters) which characterize the 
loading upon devices of a given propulsion system, can be recorded. The indices are random variables and the events of reaching a given or another value of the indices are random $[15,18,41]$.

As results from the investigations have been made so far, some quantities, e.g. $p_{e}, c_{s r}[18,26,32,34]$, characterize both mechanical and thermal loading. It obviously means that between mechanical loading and thermal loading some relations exist. As they are random processes, it may be concluded that the relations may be expected stochastic. The problem was highlighted in the work [18] in the form of a hypothesis from which it results that between the mechanical loading $Q_{M}(t)$ and thermal loading $Q_{C}(t)$ a stochastic relation takes place. As results also from this work, for a longer time of operation of the system, the hypothesis $\mathrm{H}_{2}$ which says that: "the loading upon the propulsion system is a stationary process because in a longer time of its operation there is no monotonicity of changes in the loading upon its main engine as well as of changes in the loading upon its screw propeller and shaftline, which are strictly associated with the engine loading", may be considered true. [18, 22, 27].

The hypothesis can be considered true because, as it results from the so far conducted tests of self-ignition engines, when the time interval $(\Theta)$, called range, between particular loads increases then correlation between them decreases. Therefore load values measured in the mutually far-distant time intervals may be considered independent. This feature is called asymptotic independence of load value. It occurs if the range $\Theta$ increases (Fig. 2 and 3). The independence may be proved by analyzing engine load values in the time intervals mutually far distant (e.g. by the $\Theta$ ). Dependence between the loads will be low and the lower the greater the time interval (range) $\Theta$. An example of such relation is shown in Fig.1 where changes in temperature, pressure, heat emission rate and fuel dose in cylinder (engine working space) during compression of fresh charge, fuel combustion and decompression of exhaust gas, are illustrated. The experiment whose result is given in Fig. 3, revealed consequences of lessening tension in injector spring. The lessening of the injector spring tension was simulated by applying a thinner choke. As a result, a lower pressure at injector's opening and lower injection pressure was obtained, that results in a lower velocity of fuel flow from spray nozzles and consequently a lower quality of fuel spraying. This is effected in increasing delay of self ignition [44] and in consequence in increasing maximum combustion pressure and its occurrence angle becomes close to GMP. It is accompanied sometimes with significant increase of pressure rate $(d p / d \alpha)$ in cylinder as well as increase of exhaust gas temperature $\left(t_{w}\right)$ and mean indicated pressure $\left(p_{i}\right)$. As a result, engine working space and consequently its piston-crankshaft system is thermally overloaded $\left(Q_{C}\right)$ and mechanically $\left(Q_{M}\right)$ as well $[26,27,33,34,36,41,43]$.

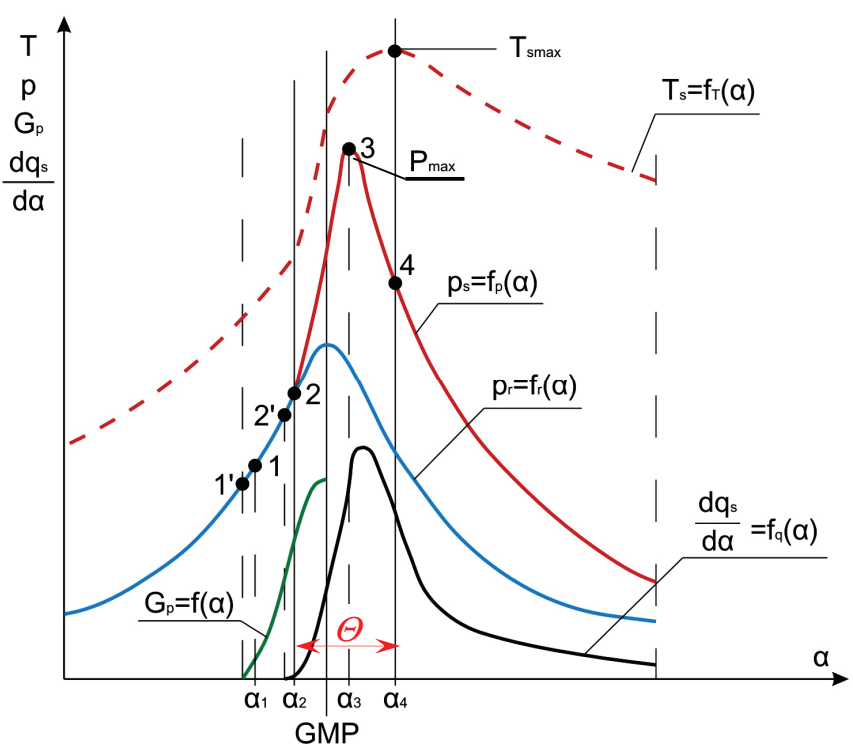

Fig. 2. Schematic diagram of run of changes in pressure and temperature as well as fuel dose and heat emission rate in cylinder of self-ignition engine, dealing with the parameters:

$p$-pressure, $T$ - temperature, $\alpha$ - crankshaft rotation angle, $p_{3}=p_{\text {max }}-$ maximum combustion pressure, $T_{\max }$ - maximum temperature, $G_{p}$-fuel dose, $q_{\mathrm{s}}-$ specific heat emitted during combustion, $d q_{\mathrm{s}} / d \alpha-$ heat emission rate values in cylinder, 1' - beginning of fuel pressure by injection pump,

1 - beginning of fuel injection into combustion chamber, 2 - formation of first sources of fuel self-ignition, 2 - beginning of fuel combustion in cylinder,

3 - maximum combustion pressure, 4 - maximum combustion temperature, $\Theta$-duration time of engine operation

The asymptotic independence of load values increases when engine wear grows. The question was signalled with growing injector spring wear which causes the lowering of injector's opening, as an example. (Fig. 3) [44].

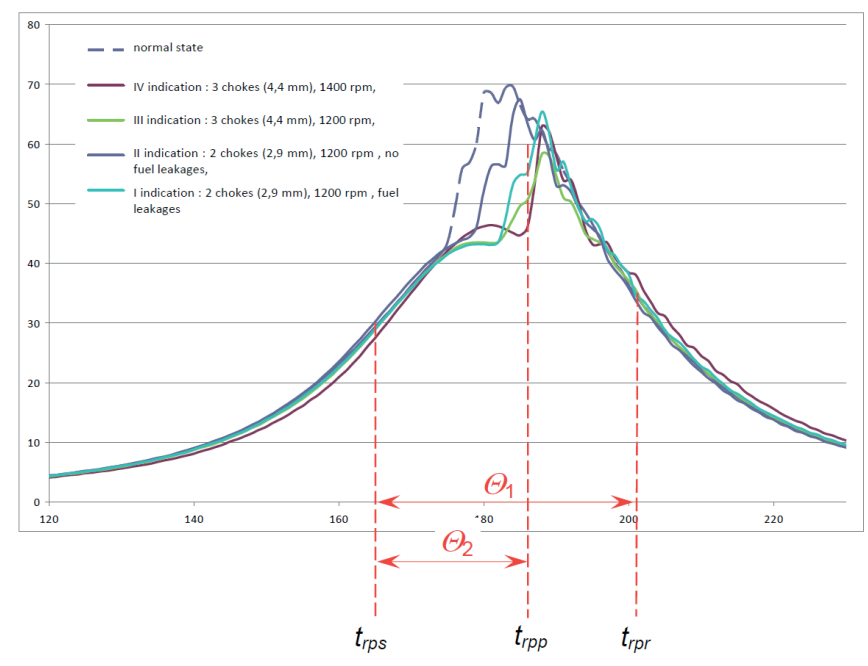

Fig. 3. Real image of indicator diagram's deformation resulting from a lower opening pressure of injector of the laboratory engine of ZS Faryman Diesel, type D [44], $t_{r p s}$ - a selected instant of execution of fresh charge compression process, $t_{r p p}$ - a selected instant of execution of fuel combustion process $t_{r p r}$ a selected instant of execution of exhaust gas decompression process, $\Theta_{1} \Theta_{2}$ - ranges of engine operation time intervals in whose beginnings and ends loads are determined.

As results from the presented considerations (Fig. 3), if the time interval (range) $\Delta t=\Theta$ increases, the loads upon the 
propulsion system $(U N)$, which occur in the instants being the ends of the interval, e.g. $\left(t_{r p s}, t_{r p p}\right)$ or $\left(t_{r p s}, t_{r p r}\right)$, are more and more independent to each other. And, it is obvious that if the instants are the beginnings and ends of small intervals, i.e. when $d t=d \Theta$, then the loads in such instants will be mutually dependent. Therefore it may be acknowledged that the Markov condition in relation to the loading upon the $U N$ may be formulated as follows: the load (thermal and mechanical) upon the propulsion system (UN) and simultaneously upon every device belonging to the system, i.e. the main engine $(S G)$, shaftline $(L W)$ and controllable pitch screw propeller (SNoSN), occurring in a given time instant, and its duration time depend only on the load directly preceding it and not on the loads which occurred earlier and their duration time intervals. Moreover, from the above presented hypothesis $H_{1}$ results that the loading which occurs during operation of the UN may be considered a stochastic process. It means that for description of the loads in function of time the theory of semi-Markov processes may be used. The conclusion may also implicate that for description of $U N$ wear resulting from its loading during service of the system, the semi-Markov processes theory may be also applied.

Differentiated (random) loads (see e.g. Fig. 3) cause irregular run of wear process in particular tribological links as well as random spread of wear rate in the combustion engine sytems $[6,11,16,25,39]$. For this reason it is necessary to identify features of the wear processes in tribological links of propulsion systems, especially in their main engines.

\section{FEATURES OF WEAR PROCESS IN TRIBOLOGICAL LINKS OF ENGINES}

The run of wear process in an arbitrary tribological link of the main engine (SG), shaftline $(L W)$ and controllable pitch screw propeller $(S N o S N)$ is influenced by initial quality of the system as well as random spread of its wear rate resulting from varying loads and lubrication conditions $[6,15,25,35,39]$.

The run of wear process in tribological links of an arbitrary device of propulsion system (SG, $L W, S N o S N)$ may be generally represented by the commonly known Lorence curve which is one of many models applicable to investigation of changes in states of such systems in a given time instant $[6,15,35,39]$. In such case, while considering run of surface (linear) wear process in a given tribological link, the following states may be taken into account: the state $z_{0}$ - in which grinding-in takes place, state $z_{1}$ - in which usual stable wear occurs, state $z_{2}$ - in which quasi-failure wear happens, state $z_{3}$ - which may lead to failure-generating wear (accelerated, disastrous) and is undesired for this reason (Fig. 4).

Run of surface wear process in all the states $z_{\mathrm{i}} \in Z(i=0,1$, $2,3)$ depends on many factors but first of all on loads upon particular tribological links. While analyzing wear process in any tribological link according to Lorence curve (Fig. 4), some its limit values may be distinguished, i.e. such wear values of a given system whose exceedance results in qualitative change in features of the system.
The following values may be certainly counted among those of practical usefulness:

- the initial wear value $\left(z_{p}\right)$ which occurs after passing the time interval $\left(0, t_{p}\right]$ during which the tribological system's wear $z_{0}$ assuring its correct grinding-in, was present;

- the permissible wear value $\left(z_{d}\right)$ which occurs after passing the time interval $\left(t_{p}, t_{d}\right]$ during which the tribological system's wear $z_{1}$ (called quasi-stable, normal wear) was present;

- the inadmissible wear (failure-generating, ultimate) value $\left(z_{n}\right)$ which occurs after passing the time interval $\left(t_{d}, t_{n}\right]$ in which the tribological system's wear $z_{2}$ being in - between stable and disastrous one, takes place - i.e that in which the initial wear of friction surfaces of the system appears, e.g. due to occurrence of initial symptoms of the seizing-up in the system,

- the disastrous wear value $\left(z_{k}\right)$ which appears after passing the time interval $\left(t_{n}, t_{k}\right)$ during which accelerated (failuregenerating, disastrous) wear showing initial phase of wearing the friction surfaces of the system took place first, that in consequence leads to growth of the seizing-up of surfaces of the system; the wear $z_{k}$ occurred at the instant $\left(t_{k}\right)$ is equivalent to disastrous (final) failure, e.g. due to seizing the system, bonding, welding its elements or melting its interacting surfaces etc., that makes its further work entirely impossible.

In case of volumetric wear, the value of disastrous wear $\left(z_{k(b)}\right)$ showing first micro-craks and then macro-cracks, appears after passing the time interval $\left(0, t_{k}\right)$.

Interpretation of the above mentioned limit values is presented in Fig.4.

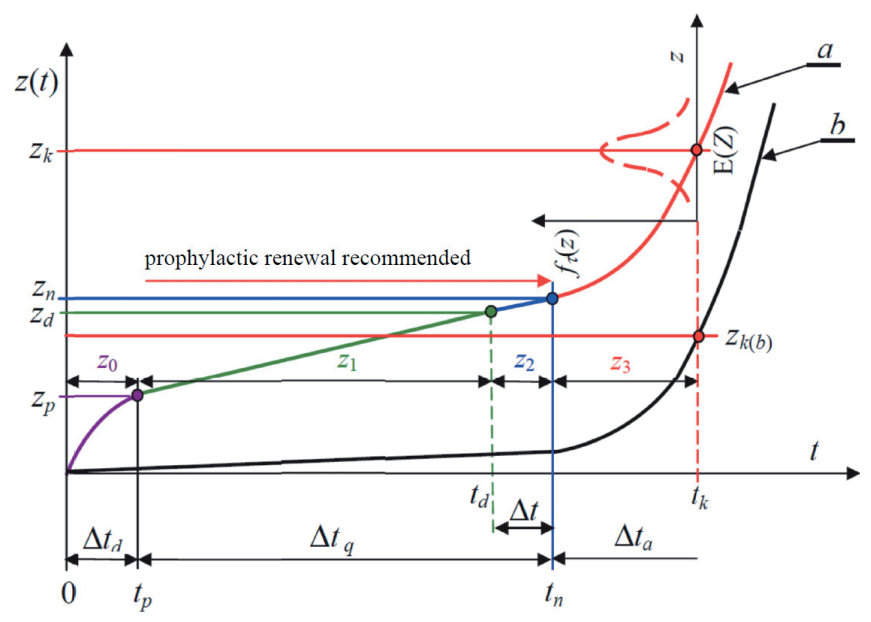

Fig. 4. Exemplary curves of typical runs of wear of slide tribological systems: $a$ - linear wear curve, $b$ - volumetric wear curve, permissible wear value, $z_{n} \cdot$ inadmissible wear value (failure generating, ultimate), $z_{k} \cdot$ disastrous wear value which causes failure of the system, $z_{\text {(b) }}$. disastrous value of volumetric wear which causes failure of the system, $\Delta t_{d} \cdot$ time interval of grinding-in process, $\Delta t \cdot$ quasi-static (normal, stable) wear time interval, $\Delta t$. failure generating (accelerated, disastrous) wear time interval, $z_{0}$ - state of the system in which grinding-in takes place, $z_{1}$ - state of the system in which stable wear takes place, $z_{2}$-state of the system in which quasi-failure wear takes place, $z_{3}$-state of the system which is leading to failure-generating (accelerated, disastrous) wear, $f_{\tau}(z)$ - wear density function of the system, $E(Z)$ - expected wear value, $z$-wear random variable, $\Delta t$ - time interval in which prophylactic servicing should start, $t$ - the instant at which the value $z$ is reached, $t_{d}$ - the instant at which the value $z_{d}$ is reached, $t_{n}$ - the instant at which the value $z_{n}$ is reached 
For practical reasons every tribological system should be considered failed when its surface (linear) wear value reaches the permissible value $\left(z_{d}\right)$. This results from that mean rate of surface (linear) wear of the system, in case of occurence of the state $z_{3}$, grows along with its operation time (curve "a" in Fig. 4). The same happens in case of volumetric wear (micro- and macro-cracks) (curve "b" in Fig. 4).

In order to prevent tribological systems ( $S G, L W, S N o S N)$ against failures appropriate servicing operations are applied to the $U N$ devices leading to renewal of particular tribological systems. The servicing operations may be undertaken (depending on a decision situation) in the time when tribological systems are in the failure-generating wear state $\left(z_{3}\right)$ or also when the systems are in the stable wear state $\left(z_{2}\right)$. The second case occurs when it results from predictions of duration time of the state $z_{2}$ of a given tribological system that it is highly probable that the remaining duration time of the state will be shorter than the time necessary to complete the ship's task which can be fulfilled then and only then when in the above mentioned system the failure-generating (disastrous) wear does not appear. In case of occurrence of such wear a failure may happen in any tribological system and consequently also in the UN device containing such system. Every such failure is random event $[6,11,15,25,39]$. Therefore the process of subsequently following technical states should be considered to be the random process $\{W(\mathrm{t}): t \geq 0\}$ whose values are the above distinguished states $s_{i} \in S(i=\overline{0,3})$ of the following interpretation:

$s_{0}$ - serviceability state of the propulsion system (UN),

$s_{1}$ - unserviceability state of the $U N$ resulting from main engine $(S G)$ failure,

$s_{2}$ - unserviceability state of the $U N$ resulting from shaftline $(L W)$ failure and

$s_{3}$ - unserviceability state of the UN resulting from failure of controllable pitch screw propeller (SNoSN).

The process $\{W(t): t \geq 0\}$ is characteristic of that the duration time $T_{i}$ of the states $s_{i} \in S(i=\overline{0,3})$ is a non-odd random variable having the distribution function $F_{i}(t)=P\left(T_{i}<t\right)$, continuous density function $f_{i}(t)=\frac{d F_{i}(t)}{d t}$ and positive expected value $E\left(T_{i}\right)=\int_{0} t f_{i}(t) d t$.

The distributions $F_{i}(t)$ of random variables $T_{i}$ and their expected values $E\left(T_{i}\right)$ can be determined by using results of properly conducted measurements of wear of particular tribological systems as well as the relationships (formulae) presented e.g. in the publications $[6,25,35,39,45,46,47]$. The duration time $T_{0}$ of the state $s_{0}$ depends on run (realization) of load and wear processes in the tribological systems of the UN. Whereas the duration times $T_{i}$ of the states $s_{i} \in S(i=\overline{1,3})$ depend on run of servicing operations and resulting $U N$ renewal. The renewal events are necessary in the case of appearing the above mentioned states $s_{i} \in S(i=\overline{1,3})$ resulting from failures in the $U N$ devices, i.e. $S G, L W$ and SNoSN, respectively.

As results from the presented analysis of loads upon the tribological systems the loads are random and for this reason it is not possible to precisely predict their values in an arbitrary instant of operation. This results from unavoidable random changes in external factors as well as mutual interaction of friction elements of every tribological system and lubricating oil present between its elements. In case of considering loads upon an arbitrary tribological system (Fig. 2 and 3) in the instants far distant from each other by the time interval $\Theta$, it may be assumed that the relation between the loads is insignificant and the lower the greater value of the above mentioned interval $\Theta[4,5,25,30,33]$. It means that the loading of tribological systems is a process of asymptotically independent increases. Therefore the following hypothesis $\mathrm{H}_{3}$ may be accepted: "every technical state $s_{i} \in S(i 0,1,2,3)$ of an arbitrary tribological system as well as its duration time significantly depends on the state directly preceding it, but not on the earlier occurred states and their duration time intervals because its loading and both the rate and increases of wear, implicated by it, are processes of asymptotically independent values".

It means that it is possible to work out such model of changes in states (important for user) of every tribological system of the $U N$ (in this case the states $s_{i} \in S(i=0,1,2,3)$ as to make duration time of an arbitrary state of the process existing in the instant $\tau_{n}$ and that of the state possible to be obtained in the instant $\tau_{n+1}$ stochastically independent on the states which occurred earlier and their duration time intervals. To fulfil the conditions is possible by applying the theory of semi-Markov processes to determining reliability and lifetime of the considered tribological systems [13, 14, 15], and this way also of the $U N$. The presented features of loads and wear processes occurring in tribological systems of $U N$ components ( $S G, L W, S N o S N$ ) as well as existing possibilities to measure loads and wear of the systems $[6,15,21,25,29,31$, $34,36,39$ ] made it possible to formulate the conclusion that the semi-Markov process of an appropriate functional matrix and known initial distribution whose values are the earlier distinguished states $s_{i} \in S(i=\overline{0,3})$ may serve as a model of the process of changes in technical state of propulsion systems on sea-going ships.

\section{MODEL OF CHANGES IN TECHNICAL STATES OF DEVICES CRUCIAL FOR SHIP SAFETY}

In operation phase of propulsion systems (UN) their devices such as main engines $(S G)$, shaftlines $(L W)$ and controllable pitch scew propellers $(S N o S N)$ suffer failures. The devices usually undergo renewal (of course if it is justified) as a result of appropriate servicing. Hence in the case of the devices in question, like in the case of other shipboard devices, model of process of changes in their reliability states may be considered to be the semi-Markov process $\{W(t): t \geq 0\}$ of the set of states $S=s_{i} ; i=0,1,2,3$. Interpretation of the states $s_{i} \in S(i=0,1,2,3)$, as already mentioned, is as follows: $s_{0}$ - serviceability state of propulsion system $(U N)$,

$s_{1}$ - unserviceability state of propulsion system (UN) resulting from main engine failure $(S G)$, 
$s_{2}$ - unserviceability state of propulsion system (UN) resulting from shaftline failure (LW) and

$s_{3}$ - unserviceability state of propulsion system (UN) resulting from failure of controllable pitch scew propeller (SNoSN).

Changes in the specified states $s_{i}(i=0,1,2,3)$ occur in subsequent instants $t_{n}(n \in \mathrm{N})$, whereas in the instant $t_{0}=0$ all the mentioned devices of the $U N$ are in the state $s_{0}$. The state $s_{0}$ lasts till the instant of failure of any of the devices. But the states $s_{i}(i=1,2,3)$ last as long as one of the mentioned devices is renewed or replaced if its renewal is not justified. Changes of the states si into the states $s_{j}(i, j=0,1,2,3 ; i \neq j)$ occur after passing the time $T_{i j}$ which is a random variable. Taking the situation into account in the operation phase of an arbitrary ship $U N$ requires to use probabilistic description with accounting for probabilities of possible occurrence of the mentioned states $s_{i}(i=0,1,2,3)$ in particular instants $t_{0}, t_{1}, \ldots, t_{n \cdot 1}$, $n$ of ship's $U N$ operation time $[2,5,6,20,23,38]$. As results from the presented considerations the mentioned states $s_{i}(i=0,1,2,3)$ so appear in particular instants of propulsion system's operation time as it is possible to state that:

1) the Markov condition is satisfied, namely, the future evolution of technical states of any device of ship propulsion system, i.e. its main engine, shaftline and screw propeller (and - consequently - process of changes in their technical states) depends only on a state existing in a given instant but not on functioning that propulsion system in the past, hence the future of the devices in question does not depend on its past but only on its present ;

2) the random variables $T_{i}$ and $T_{i j}$ have distributions other than exponential, where: $T_{i}$ - stands for duration time of the state $s_{i}$ irrespective of which state will follow it, and $T_{i j}$ - stands for duration time of the state $\mathrm{s}_{\mathrm{i}}$ under condition that the next state of the process will be the state $s_{j}$.

Hence it may be assumed that the state of the UN and consequently the state of the devices in question ( $S G, L W$, $S N o S N$ ) in the instant $t_{n+1}$ as well as the duration time interval of the state reached in the instant $t_{n}$ does not depend on the states which occurred in the instants $t_{0}, t_{1}, \ldots, t_{\mathrm{n} \cdot 1}$ as well as on their duration time intervals. Therefore the four-state, time-continuous, semi-Markov process $\{W(t): t \geq 0\}$ of the states $s_{0}, s_{1}$ i $s_{2}, s_{3}$ may serve as a model of the real process $\{V(t): t \geq 0\}$ of changes in $U N$ states $[9,15,10,12,13,30]$. The graph of the process is given in Fig. 5.

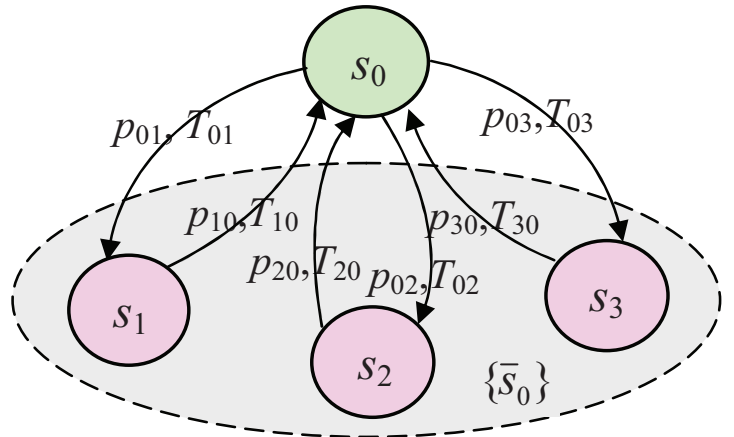

Fig. 5. Graph of changes in the states of the process $\{W(t): t \in T\}$ : $s_{0}$ - serviceability state of $U N,\left\{\bar{s}_{0}\right\}$ - the set of unserviceability states of the devices (SG, LW, SNoSN): $\left\{\bar{s}_{0}\right\}=\left\{s_{1}, s_{2}, s_{3}\right\}$,

$s i \in S(i=0,1,2,3)$ - states of the following interpretation: $s_{0}$ - serviceability state of UN, $s_{1}-$ unserviceability state of UN due to main engine failure (SG),

$s_{2}-$ unserviceability state of UN due to failure of shaftline (LW) and $s_{3}$

unserviceability state of UN due to screw propeller failure (SNoSN),

$T_{i j}$-duration time of the state si under condition that the next will be the state $s_{j}(i, j=0,1,2,3 ; i \neq j)$, pij-probability of passing the process $\{W(t): t \in T\}$ from the state $s_{i}$ to the state $s_{j}(i, j=0,1,2,3 ; i \in j)$.

The initial distribution of the process is as follows:

$$
P\left\{W(0)=s_{i}\right\}=\left\{\begin{array}{lll}
1 & \text { dla } & i=0 \\
0 & \text { dla } & i=1,2,3
\end{array}\right.
$$

and its functional matrix has the following form:

$$
\mathbf{Q}(\mathbf{t})=\left[\begin{array}{cccc}
0 & Q_{01}(t) & Q_{02}(t) & Q_{03}(t) \\
Q_{10}(t) & 0 & 0 & 0 \\
Q_{20}(t) & 0 & 0 & 0 \\
Q_{20}(t) & 0 & 0 & 0
\end{array}\right]
$$

The functional matrix $Q(t)$ constitutes mathematical description of changes in the $U N$ reliability states and consequently its devices in question. The non-zero elements $Q_{i j}(t)$ of the functional matrix $Q(t)$ depend on distributions of random variables which are time intervals of staying the process $\{W(t): t \geq 0\}$ in the states $s_{i} S(i=0,1,2,3)$. Elements of the matrix are probabilities of passing the considered process from the state $\mathrm{s}_{\mathrm{i}}$ to the state $s_{j}\left(s_{i}, s_{j} \in S\right)$ during the time not longer that $t$, which are determined as follows $[13$, 15, 19]:

$Q_{i j}(t)=P\left\{W\left(\tau_{n+1}\right)=s_{j}, \tau_{n+1}-\tau_{n}<t \mid W\left(\tau_{n}\right)=s_{i}\right\}=p_{i j} F_{i j}(t)$

where:

$p_{i j} \quad$ - probability of passing the Markov uniform chain in one step:

$p_{i j}=P\left\{W\left(\tau_{\mathrm{n}+1}\right)=s_{j} \mid W\left(\tau_{n}\right)=s_{i}=\lim _{t \rightarrow \infty} Q_{i j}(t)\right.$,

$F_{i j}(t)$ - distribution function of the random variable $T_{i j}$ determining the duration time of the state $s_{i}$ of the process $\{W(t): t \geq 0\}$ under condition that its next state will be the state $s_{j}$. 
As results from the functional matrix $Q(t)$ (2), the matrix $P$ of probabilities of passing the Markov chain inserted into the process, is the following $[8,9,15,19,38]$ :

$$
\mathbf{P}=\left[\begin{array}{cccc}
0 & p_{01} & p_{02} & p_{03} \\
1 & 0 & 0 & 0 \\
1 & 0 & 0 & 0 \\
1 & 0 & 0 & 0
\end{array}\right]
$$

In the process $\{\mathrm{W}(\mathrm{t}): \mathrm{t} \geq 0\}$ the random variables $T_{i j}$ have determined positive expected values. Therefore its distribution is limited $[8,9,15,19]$ as follows:

$P_{j}=\lim _{t \rightarrow \infty} P_{i j}(t)=\lim _{t \rightarrow \infty} P\left\{W(t)=s_{j}\right\}, s_{j} \in S(j=0,1,2,3)$

and has the following form:

$$
P_{j}=\frac{\pi_{j} \mathrm{E}\left(T_{j}\right)}{\sum_{k=0}^{3} \pi_{k} \mathrm{E}\left(T_{k}\right)}
$$

The probabilities $\pi_{j}(j=0,1,2,3)$ in the formula (7) are limit probabilities of Markov chain inserted into the process $\{W(t): t \geq 0\}$. Whereas $\mathrm{E}\left(T_{j}\right)$ and $\mathrm{E}\left(T_{k}\right)$ are expected values of random variables in the state $s_{j}$ and $s_{k}$, respectively, irrespective of which state the system will pass in the future to.

Determination of the limit distribution (7) requires to solve the set of equations which contain the above mentioned limit probabilities $\pi_{j}(j=0,1,2,3)$ of inserted Markov chain into the process $\{W(t): t \geq 0\}$ as well as the matrix $P$ of probabilities of passing from the state $s_{i}$ to the state $s_{i}$ determined by the formula (5). Such set has the following form:

$$
\begin{gathered}
{\left[\pi_{0}, \pi_{1}, \pi_{2}, \pi_{3}\right]=\left[\pi_{0}, \pi_{1}, \pi_{2}, \pi_{3}\right] \cdot\left[\begin{array}{cccc}
0 & p_{01} & p_{02} & p_{03} \\
1 & 0 & 0 & 0 \\
1 & 0 & 0 & 0 \\
1 & 0 & 0 & 0
\end{array}\right]} \\
\sum_{k=1}^{4} \pi_{k}=1
\end{gathered}
$$

As a result of solving the set of equations (8) it is possible to obtain, by using the formula (7), the following relations:

$$
\begin{aligned}
& P_{0}=\frac{E\left(T_{0}\right)}{E\left(T_{0}\right)+\sum_{k=1}^{3} p_{0 k} E\left(T_{k}\right)}, P_{1}=\frac{p_{01} E\left(T_{1}\right)}{E\left(T_{0}\right)+\sum_{k=1}^{3} p_{0 k} E\left(T_{k}\right)}, P_{2}=\frac{p_{02} E\left(T_{2}\right)}{E\left(T_{0}\right)+\sum_{k=1}^{3} p_{0 k} E\left(T_{k}\right)}, \\
& P_{3}=\frac{p_{03} E\left(T_{3}\right)}{E\left(T_{0}\right)+\sum_{k=1}^{3} p_{0 k} E\left(T_{k}\right)},
\end{aligned}
$$

The probability $\mathrm{P}_{0}$ is limit probability that in a longer time of operation (theoretically at $t \rightarrow \infty$ ) the devices in question ( $S G, L W, S N o S N)$ remain in the state $s_{0}$. Therefore the probability determines a technical operational availability factor of the $U N$ as well as of the devices in question. Whereas the probabilities $P_{j}(j=1,2,3)$ are limit probabilities of existence of the states $s_{j} \in S(j=1,2,3)$ of the devices in question at $t \rightarrow \infty$, i.e. the probabilities of their passing to unserviceability states due to failure.

Fig. 6 shows an exemplary realization of the process $\{W(t): t \geq 0\}$, which illustrates appearing the reliability states $s_{j} \in S(j=1,2,3)$ of any $U N$ and consequently its devices during operation. In order to obtain values of the probabilities $P_{j}(j=0,1,2,3$,$) (of course approximate ones) it is necessary$ to estimate $p_{i j}$ as well as $\mathrm{E}\left(T_{j}\right)$.

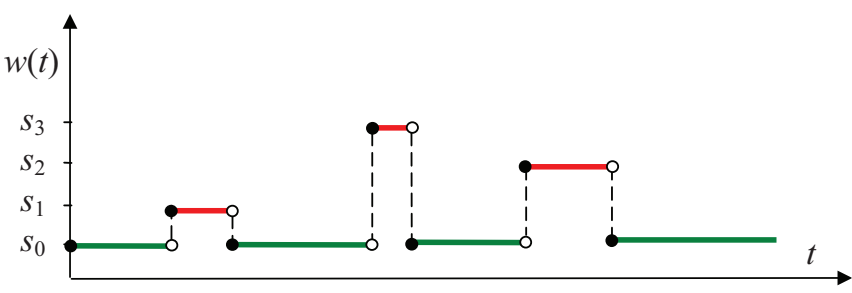

Fig. 6. Exemplary realization of the process $\{W(t): t \geq 0\}$ of ship's $U N$ and its devices (SG, LW, SNoSN): s - serviceability state of $U N$ and its devices, $s_{1} \cdot$ unserviceability state of $S G, s_{2} \cdot$ unserviceability state of $L W$ $s_{3} \cdot$ unserviceability state of SNoSN.

To estimate the probabilities $p_{i j}$ and the expected values $E\left(T_{j}\right)$ is possible after obtaining realization of $w(t)$ of the process $\{W(t): \mathrm{t} \geq 0\}$ in an appropriately long time interval of observation, i.e. for $t \in\left[0, t_{b}\right]$, where the observation time of the process: $t_{b} \gg 0$. It is then possible to determine the numbers $n_{i j}(i, j=0,1,2,3 ; \mathrm{i} \neq \mathrm{j})$ of transition of the process $\{W(t): t \geq 0\}$ from the state $s_{i}$ to $s_{j}$ in an appropriately long time and to determine values of the estimator $\hat{P}_{i j}$ of unknown probability $p_{i j}$. The below given statistics $[15,19]$ is the highest credibility estimator for the transition probability $p_{i j}$;

$$
\hat{P}_{i j}=\frac{N_{i j}}{\sum_{j} N_{i j}}, \quad i \neq j ; i, j=0,1,2,3,
$$

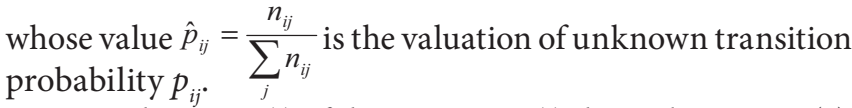

From the run $w(t)$ of the process $W(t)$ the realizations $t_{j}^{(m)}$, $m=1,2, \ldots, n_{i j}$ of the random variables $T_{j}$, can be obtained. Due to application of point estimation it possible to easily estimate $\mathrm{E}\left(T_{j}\right)$ as mean arithmetic value of the realizations $t_{j}^{(m)}$.

In order to obtain required information for estimation of the probabilities in question it is necessary to apply an appropriate diagnostic system $(S D G)$ to the considered devices of the $U N$, which, in this case, are the diagnosed systems $(S D N)[13,15,42,43,45,46,47]$. 


\section{FINAL REMARKS AND CONCLUSIONS}

The formulae for determining the reliability indices of propulsion systems were worked out on the basis of application of limit distribution of the semi-Markov process $W(t): t \geq 0\}$. To determine such distribution is easier than the instantaneous distribution constituted by the functions $P_{k}(t)(k=0,1,2,3)$ which determine probabilities of the event that in an arbitrary instant $t$ the process will be in the state $s_{\mathrm{i}} \in S(i=0,1,2,3)$. Such distribution can be determined by using the initial distribution (2) of the process in question as well as the functions $P_{i j}(t)$ which determine the conditional probabilities (4), called also the probabilities of transition of the process from the state $s_{i}$ to the state $s_{j}\left(s_{i}, s_{j} \in S, i, j=1\right.$, $2,3 ; \mathrm{i} \neq \mathrm{j})$. Calculation of the probabilities $P_{k}(t)$ consists in solving the set of Voltera $2^{\text {nd }}$ kind integral equations [19] whose known quantities are (in this case) elements of the functional matrix (3).

Generally, when number of states is rather low and functional matrix - rather non-sophisticated in mathematical sense then the above mentioned set of equations can be solved by using operational calculus with the aid of Laplace-Stieltjes transform. A larger number of states or more complicated stochastic matrix makes that such set can be only solved in an approximate way by means of an appropriate numerical procedure.

The proposed semi-Markov process is the simplest model of changes in crucial states of ship propulsion systems (UN) and their devices such as $S G, L W$ and SNoSN. Obviously, the model may be modified depending on needs resulting from utilitarian aims and/or cognitive ones assumed for investigations concerning every kind of the considered devices.

The presented model of the process of changes in states of $U N$ devices is the four-state, time-continuous semi-Markov process.

The offered considerations concern first of all tribological systems of main engines $(S G)$ such as their main and crankshaft bearings as well as the piston-piston rings-cylinder sleeve systems. However they are also applicable to thrust and journal bearings of shaftline $(L W)$ as well as bearings of controllable pitch screw propellers $(S N o S N)$, i.e. of such their units as pitch changing mechanism (MZSS), blade rotation mechanism (MOSS) and propeller transmitter (NSN).

Hypotheses have been proposed as to why it may be assumed that loading process of any propulsion system can be considered a stationary stochastic process of asymptotically independent increases as well as that there is a stochastic dependence between its thermal and mechanical loads.

The presented considerations concerning features of wear in propulsion systems $(U N)$ were focused mainly on surface (linear) wear of slide bearings, but it was also mentioned that such features may be also assumed characteristic for volumetric wear (micro- and macro-cracks) of $U N$ devices.

\section{BIBLIOGRAPHY}

1. Aeberli K.: New high-economy engines for Panama containerships and large tankers, Wartsila Switzerland Ltd, Winterthur, September 2007.

2. Benjamin J. R., Cornell C. A.: Probability calculus, mathematical statistics and decision theory for engineers (in Polish). WNT, Warszawa 1977.

3. Bielaczyc P., Merkisz J., Pielecha J.: Thermal state of combustion engine and emission of noxious compounds (in Polish). Wydawnictwo Politechniki Poznańskiej, Poznań 2001.

4. Brun R.: High-speed diesel engines (in Polish). WKiŁ, Warszawa 1973. Original edition : Science et Technique du Moteur Diesel Industriel et de Transport. Copyright by Societe des Editions Technip ? et Institut Francais du Petrole, Paris 1967.

5. Firkowicz S.: Statististical assessment of quality and reliability of electronic lamps (in Polish). WNT, Warszawa 1963.

6. Gercbach I.B., Kordonski Ch.B.: Reliability models of technical objects (in Polish). WNT, Warszawa 1968.

7. Gichman I.I, Skorochod A.W.: Introduction to theory of statistical processes (in Polish). PWN, Warszawa 1968.

8. Girtler J., Kuszmider S., Plewiński L.: Selected issues of operation of sea-going ships in the aspect of navigation safety (in Polish). Monograph. WSM, Szczecin 2003.

9. Girtler J., Kitowski Z., Kuriata A.: Ship safety at sea. System's approach (in Polish). WKiŁ, Warszawa 1995.

10. Girtler J.: Probability as a measure of operational safety of technical objects (in Polish). Materials of $7^{\text {th }}$ Scientific Conference „Safety of systems”. PTBiN, PTC, SPE KBM PAN, STŚT KT PAN, Wydział Transportu PW, ITWL, Warszawa-Zakopane-Kościelisko 1998, pp.163-168.

11. Girtler J.: Stochastic model of load spectrum of self-ignition engine (in Polish). Zagadnienia Eksploatacji Maszyn, PAN quarterly, iss. 1/97, 1994.

12. Girtler J.: A concept of decision-making process with taking into account reliability and safety of sea transport means (in Polish). Materials of Domestic Conference on Safety and Reliability, Vol.1. ITWL, Warszawa-Zakopane-Koscielisko 1999, pp. 289-296.

13. Girtler J.: Diagnostics as a condition for control over ship combustion engines in operation (in Polish). Studies No. 28. WSM, Szczecin 1997. 
14. Girtler J.: Physical aspects of application and usefulness of semi-Markov processes for modelling the processes occurring in operational phase of technical objects. Polish Maritime Research, No. 3 (41)/2004, Vol. 11, pp. 25-30.

15. Girtler J.: Control over ship combustion engines in operation on the basis of diagnostic decision - making process (in Polish). ZN AMW, No. 100A, Gdynia 1989.

16. Girtler J.: Stochastic model of operation process of ship combustion engine (in Polish). ZEM, PAN, quarterly, iss. 2/1989, s. $79-88$.

17. Girtler J.: Quantum issues in diagnostics of marine energy machines and devices. Zeszyty Naukowe Akademii Morskiej w Szczecinie, No. 30 (102), 2012, pp. 37-45.

18. Girtler J.: Identification of damages of tribological associations in crankshaft and piston systems of two-stroke internal combustion engines used as main propulsion engines on sea-going vessels and proposal of probabilistic description of loads as causes of these damages. Polish Maritime Research. No. 2 (86)/2015, Vol. 22, pp. 44 - 54.

19. Grabski F.: Theory of semi-Markov processes of operation of technical objects (in Polish). ZN WSMW, No. 75A, Gdynia,1982.

20. Gniedenko B.W., Bielajew J.K., Sołowiew A.D: Mathematical methods in theory of reliability (in Polish). WNT, Warszawa,1968.

21. Höglund P.G., Ydstedt A.: Reduced Air Pollution and Fuel Consumption with Preheated Car Engines. Urban Transport and the Environment for the $21^{\text {st }}$ Century, International Conference, Lisbon 1998.

22. Korczewski Z.: Exhaust gas temperature measurements in diagnostics of turbocharged marine internal combustion engines. Part II: Dynamic measurements. Polish Maritime Research. No. 1 (89)/2016, Vol. 23, pp. 68 - 76.

23. Krzysztofiak M., Urbanek D.: Statistical methods (in Polish). PWN, Warszawa 1979.

24. Lewitowicz J.: Impact of physical processes onto diagnostic systems of technical objects (in Polish). Materials of $3^{\text {rd }}$ School of Systems Engineering. Warszawa-Kiekrz, ITWL 1987, pp. 71-85.

25. Niewczas A.: Background for stochastic model of friction wear in issues of lifetime of machine elements (in Polish). Zeszyty Naukowe, Mechanika, No. 19, Politechnika Radomska 1989.

26. Piotrowski I.: Ship combustion engines (in Polish). WM, Gdańsk 1971.
27. Piotrowski I., Witkowski K.: Operation of ship combustion engines (in Polish). Maritime Academy, Gdynia, 2002.

28. Plewiński L.: Accidents at sea. Collisions of ships (in Polish). Publ. WSM, Szczecin, 2000.

29. Rozanov Ju.A.: Stacionarnye slučajnye processy (in Russian). Fizmatgiz, Moskva 1963.

30. Rudnicki J.: Application isssues of the semi-Markov reliability model. Polish Maritime Research. No. 1 (85)/2015, Vol. 22, pp. $55-64$.

31. Voinov A.N.: Sgoranie v bystrochodnych poršnevych dvigateliach (in Russian). Mašinostroenie, Moskva, 1977.

32. Voznickij I.B., Ivanov Ł.A.: Predotvrascenie avarij sudovych dvigatelej vnutrennego sgorania (in Russian). Transport, Moskva, 1971.

33. Wajand J.A., Wajand J.T.: Medium- and high-speed combustion engines (in Polish). WNT, Warszawa, 2005.

34. Wieszkielski S.A., Łukianczenko B.S.: Techniczeskaja eksptuatacja dvigatielej vnutrennego sgorania (in Russian). Maszinostroenie, Leningrad, 1978.

35. Włodarski J.K.: Piston combustion engines. Tribological processes (in Polish). WKiŁ, Warszawa,1981.

36. Włodarski J.K.: Operational states of ship combustion engines (in Polish). WSM, Gdynia, 1998.

37. Wojnowski W.: Ship power plants (in Polish). Publ. AMW, Gdynia, 1998.

38. Reliability handbook (in Polish). Multi-author work. Ed.: J. Migdalski, Wydawnictwa Przemysłu Maszynowego „WEMA”, Warszawa, 1982.

39. Selected issues concerning wear of materials in sliding joints of machines (in Polish). Multi-author work. Ed.: W. Zwierzycki. PWN, Warszawa-Poznań, 1990.

40. Marine Chamber's statements on failures of main and auxiliary self-ignition combustion engines (in Polish).

41. Girtler J.: Identification of operational conditions of crankshaftpiston systems of ship main engines (in Polish). A stage report on realization of the project No. N N509 494638 financed by MNiSW. The author's research project on: „Decision making control over operation of crankshaft-piston systems of main propulsion engines on sea-going ships with application of technical diagnostics and taking into account safety and protection of the environment". Project's superviser: J. Girtler. Prace badawcze No. 1/10/PB. Faculty of Ocean 
Engineering and Ship Technology, Gdańsk University of Technology, 2010.

42. Girtler J., Łosiewicz Z.: Analysis of diagnostic model of engine crankshaft-piston systems, adjusted to needs of control of operation process of the engines in the aspect of ship and environment safety (in Polish). A stage report on realization of the project No. N N509 494638 financed by MNiSW. The author's research project on: „Decision - making control over operation of crankshaft-piston systems of main propulsion engines on sea-going ships with application of technical diagnostics and taking into account safety and protection of the environment". Project's superviser: J. Girtler. Prace badawcze No. 6/10/PB. Faculty of Ocean Engineering and Ship Technology, Gdańsk University of Technology, 2010.

43. Girtler J., Fydrych J.: Analysis and assessment of usability of the worked out diagnostic system for ship main engines, intended for control of operation process of such engines in the aspect of assuring safety of ships and marine environment (in Polish). The author's research project on: „Decisionmaking control over operation of crankshaft-piston systems of main propulsion engines on sea-going ships with application of technical diagnostics and taking into account safety and protection of the environment". Project's superviser: J. Girtler. Prace badawcze No. 4/12/PB. Faculty of Ocean Engineering and Ship Technology, Gdańsk University of Technology, 2012.

44. Korczewski Z.: Determination of principles for verification of diagnostic model and its possible modification for needs of rational control over operation process of engines (in Polish). The work done within frames of the author's research project titled: „Decision - making control over operation of crankshaft-piston systems of main propulsion engines on sea-going ships with application of technical diagnostics and taking into account safety and protection of the environment". Project's superviser: J. Girtler. Prace badawcze No. 28/11/PB. Faculty of Ocean Engineering and Ship Technology, Gdańsk University of Technology, 2011.

45. UP RP Patent No. 211232 issued for the invention: „The stand for preparation of classifiers for identification failure states of bearings, especially these in self-ignition engines, based on application of acoustic emission to form diagnostic signal “ (in Polish) Its authors: Jerzy Girtler, Wojciech Darski, Ireneusz Baran, Marek Nowak, Artur Olszewski, Jerzy Schmidt, Gdańsk University of Technology. The patent was worked out as a result of realization of the authors' research project No. N504 043 31/3480 financed by MNiSzW.

46. UP RP Patent No. 224702 issued for the invention: „The diagnostic system adjusted to identification of technical state of sleeves of slide bearings of piston combustion engines, based on application of acoustic emission to form diagnostic signal “ (in Polish). Its authors: Girtler J., Darski
W., P. Darski, Gdańsk University of Technology. The patent was worked out as a result of realization of the authors' research project No. N N509 494638 financed by MNiSzW.

47. UP RP Patent No. 223940 issued for the invention: „ The diagnostic system adjusted to identification of technical state of controllable pitch screw propeller for the needs of its operation control, especially on sea-going ships “ (in Polish). Its authors: Girtler J., Darski W., Frydrych J., Gdańsk University of Technology. The patent was worked out as a result of realization of the authors' research project No. N N509 494638 financed by MNiSzW.

\section{CONTACT WITH THE AUTHOR}

\section{Jerzy Girtler}

Gdańsk University of Technology

11/12 Narutowicza St. 80 - 233 Gdańsk

Poland 